\title{
Views and experiences of people with intellectual disabilities regarding intimate relationships: A qualitative metasynthesis
}

\begin{abstract}
$\underline{\text { Abstract }}$
The aims of this review were to systematically identify, critically appraise and synthesize the results of existing qualitative literature exploring the views and experiences of intimate relationships amongst people with intellectual disabilities. Fourteen peer-reviewed articles were identified through a systematic search of eight databases, reference lists, citations, and relevant journals. The identified articles were appraised for quality, then synthesized using a metaethnography approach. No study met all quality criteria and references to ethical approval were often lacking. Interpretation of the findings suggested three key themes: the meaning of intimate relationships, external constraints and facilitators, and managing external constraints. Though many people with intellectual disabilities desire and benefit from intimate relationships, they experience restrictions that others do not, which can lead to isolation and loneliness. Intimate relationships are not always necessarily linked with sexual behavior; therefore, intimate relationships warrant their own focus in future research, as well as in education and training for people with intellectual disabilities and their caregivers. Within this, a commitment to transparency over research processes is needed, in particular with reference to how ethical approval was obtained, since this has been a shortcoming of research with this focus to date.
\end{abstract}

Keywords: Intellectual disabilities, intimate relationships, romance, couples, metasynthesis, United Kingdom.

The author would like to thank Dr Jennifer Clegg (Institute of Mental Health, University of Nottingham) for her advice. 


\section{$\underline{\text { Introduction }}$}

Historically, the sexual expression of people with intellectual disabilities (PWID) has been ignored, with PWID perceived as child-like, asexual, vulnerable to sexual abuse, or sexually deviant [1-4]. The 'normalization' principle [5,6] challenged this, asserting PWID are entitled to an 'ordinary life', including intimate relationships [7]. This became enshrined in the United Nations Convention on the Rights of Persons with Disabilities [8] and the UK government's 'Valuing People' white paper [9], both stating that PWID have the same rights to marriage and relationships as anyone else. However, in 2009 the Department of Health acknowledged that many clinicians and caregivers were still not recognizing that PWID want and need personal and sexual relationships, and more enabling practice around relationships was needed [10].

Research exploring why such 'enabling practice' has not naturally flowed from the shifts at policy level has focused on caregivers' attitudes to the sexuality of PWID. In a qualitative metasynthesis, Rushbrooke, Murray and Townsend [11] found that those providing care to PWID harbour an ambivalence between enabling sexuality and protecting individuals by restricting it, believing the former leaves individuals vulnerable to abuse or unsafe practice, or themselves vulnerable to accusations of not managing risk. A potential limitation of this metasynthesis was that Rushbrooke et al. [11] included studies that elicited the views of both parents and formal carers, despite prior research suggesting that the views of each group are often different, with that of parents being more negative/protective $[12,13]$. However, the authors managed this well by explicating the commonalities and distinctions between the difficulties experienced by paid carers up against family members. A notable distinction perhaps offering some insight into what contributes to the differing standpoints is that while both types of caregiver often feel uncomfortable acknowledging the sexual desires of those they work with, formal caregivers often deal with this by focusing on their 'professional' role over their 'mothering' role, where informal caregivers do not have that option [11]. Caregiver ambivalence has also been described as manifest in feelings of personal responsibility when relationships are facilitated, resulting in it being done in an overly restrictive way - through monitoring and controlling, caregivers have become 'the new institutional walls' [14, p. 197]. Therefore, there has been a shift from the sexuality of PWID being denied, to it being 'managed' [2,15], resulting in little change in the level of restriction experienced by PWID [16].

PWID appear to strive for a 'normal' identity [17] and in doing so tend to internalize the attitudes of carers [1820], so if their genuine opinions and desires are not sought, we cannot really know their needs. The recent 
emergence of self-advocacy movements and inclusive research for PWID has led to an increase in research giving voice to this population [21]. Though the focus again tends to be on sexuality generally, the topic of intimate relationships consistently emerges within findings [18,22]. An intimate relationship is defined here as a relationship with another person that involves emotional and physical closeness, is consensual, and is considered romantic and/or sexual in nature by both parties. Intimate relationships are associated with enhanced mental well-being [23] and quality of life [24]. The desires and benefits of such relationships for PWID appear to generally match that of the general population [25], with enhanced quality of life [24,26-29], mental health [30], and emotional well-being [31] reported. However, a large scale UK survey of PWID found that only $4 \%$ were in an intimate (couple) relationship [32], compared to $60 \%$ of the general population reported to be either married or cohabiting in the 2011 census [33]. Furthermore, the social circles of PWID tend to be smaller than those of the general population [34], with these mainly made up of staff or family members [35]. Overall, this demonstrates that despite shifts in policy, the needs of PWID in developing intimate relationships are not being met.

PWID lack support from adequate sex education $[22,36]$ and where it does exist it tends to focus on biology, with issues around relationships ignored [37]. Zigler [38,39] has conceptualized the impact of this and the lack of support more generally from a developmental perspective, suggesting that PWID have the same needs as others since they go through the same developmental stages, though they move through these stages more slowly and often need social and emotional support in acquiring the skills to do so. The prevailing apprehension in fully supporting relationships is leaving PWID ill-equipped to form appropriate, consensual and safe relationships [40]. This and the limited opportunities to develop intimate relationships leads to isolation and loneliness [41]. Therefore, understanding how these relationships are developed, experienced and understood by PWID would be beneficial in informing how they can best be supported. Unfortunately, aside from a handful of quantitative surveys focused on the incidence and success rates of marriages [42-44] that pre-date policy shifts, research specifically on intimate relationships in PWID has been sparse. Until recently there has been little added to this research base, but with the importance of intimate relationships to PWID beginning to be acknowledged $[1,14,45]$ more studies are emerging. Therefore our aim was to systematically identify, critically appraise and synthesize the results of existing qualitative literature to date, to develop a coherent and accessible understanding of the views and experiences of intimate relationships amongst PWID. 


\section{Method}

The metasynthesis was approached from a critical realist epistemological position, which assumes that any reality that does exist can only be understood through our own perceptions of it. While two of the authors have a background and interest in working with clinically PWID, the third has little experience working with this population, though has a clinical and research interest in the social and psychological constructions of gender, sex, and sexuality. The authors' different contexts allowed for reflexive dialogue and triangulation around interpretations made throughout the process of the metasynthesis, with potential bias (or perspectives) consistently monitored for and interrogated.

\section{Searching}

A systematic search was undertaken on $20^{\text {th }}$ October 2016 across Medline, Embase, CINAHL, ASSIA, AMED, PsychINFO, Web of Science and Academic Search Complete databases. Search terms were ${ }^{1}$ : ((Intellectual* or learn* or development*) adj2 (disabil* or disabl* or disord* or dysfunct* or impair*)).mp.; (mental* adj2 retard*).mp.; ((sexual* or intimate* or close* or personal* or interpersonal*) adj2 (relation* or partner* or behav* or orientat*)).mp.; (experien* or attitud* or percept* or perceiv*).ti,ab.. In addition, where terms mapped onto a subject heading or thesaurus term, these items were included in the relevant database. For example, in Embase intellectual disability maps on to the term 'intellectual impairment', therefore the latter was included in the Embase search.

To identify further studies, reference list and citations searches (Google scholar) were performed on studies meeting the inclusion criteria. Since qualitative research can be difficult to identify through database searching [46], the Journal of Applied Research in Intellectual Disabilities, the Journal of Intellectual Disability Research and Sexuality and Disability were hand searched, as they had appeared regularly in the search results and are key publications in this area.

\section{Selection}

The Preferred Reporting Items for Systematic Reviews and Meta-Analyses (PRISMA) statement [47] was adhered to for the selection procedure and the results of the process are outlined in figure 1. Studies were included if they:

\footnotetext{
${ }^{1}$ Command line syntax and reserve words adapted to meet the requirements of each database.
} 
- were written in English language

- $\quad$ were published in a peer-reviewed journal

- $\quad$ included participants who were adults ( $\geq 18$ years) with an intellectual disability ${ }^{2}$ (or previous labels for this diagnosis, e.g. learning disability, mental retardation)

- investigated first-hand experience and/or understanding of 'intimate relationships', as defined above

- $\quad$ used qualitative methods, which we defined as studies that used 'discursive' methods (e.g., interviews, focus groups, diaries, etc.) to collect data.

Studies were excluded if:

- $\quad$ they used mixed methods and the qualitative data could not be extracted separately

- they included participants without ID, such as carers, and the data from PWID could not be extracted separately

- they included participants under 18 years old, and the data from PWID $\geq 18$ years could not be extracted separately

- intimate relationships were not the primary focus

- focus was on only a specific aspect of relationships, e.g. arranged marriage

\section{Critical appraisal}

We used the Joanna Briggs Institute (JBI) [49] tool to appraise quality. This tool is more sensitive in assessing validity than others [50] and includes a check of interpretive validity, important since limited richness can occur in responses of participants with ID [51], which potentially tempts researchers into interpretative leaps. The JBI tool identifies 10 quality criteria to be applied to each article (see table 2). Although the tool uses the 'No', 'Unclear', and 'Yes' format to identify the presence or absence of criterion, it was adapted within this study to 0,1 , and 2 respectively. This allowed each paper to be given an overall quality score, and made the comparison of overall quality between studies clearer. An additional criterion was included regarding the recruitment process since caregivers often have a role in selecting potential participants in research with PWID and, as highlighted above, there are still mixed attitudes held by those in this role regarding the sexuality and relationships of PWID.

\footnotetext{
${ }^{2}$ Those who appear to meet the current diagnostic criteria [48].
} 
The studies were appraised by each of the authors independently, using the checklist. In spite of the anchoring guidance provided by the Joanna Briggs Institute [49] for each item of the tool, there is still some overlap between the items. However, this may be a necessary evil in order to retain the wider insights into the subject of interest that could be lost through an overly rigid formulaic approach to appraisal [52] (through the disqualifying of less rigorous studies), and has the benefit of encouraging raters to be explicit about their reasons for judgements [53]. Discrepancies that arose between authors' ratings were resolved through discussion.

\section{Metasynthesis of findings}

We synthesized the data using Noblit and Hare's [54] meta-ethnography approach. After reading and re-reading the studies, the findings and conclusions of each were systematically abstracted into a structured framework (self-developed data-extraction form) in terms of raw data (direct citations of participant responses - 'firstorder' constructs), author interpretations, author commentary and discussions. The themes and key concepts documented in each study ('second-order' constructs) were then identified and grouped together to form initial synthesis themes ('third-order' constructs). Common themes were then identified within the first-order constructs and author commentary across all studies through a process of 'reciprocal translation' [54] - concepts appearing across multiple studies are grouped. The third-order themes were adapted where necessary to accommodate the relevant subsets of first-order constructs, which included a process of 'refutational synthesis' [54] - contrasting findings around a singular concept are incorporated under a theme which acknowledges the disparity between findings. The process eventually resulted in a set of themes (some including subthemes) that encapsulated the findings provided by all included studies, allowing for the development of a 'line of argument' synthesis, through which new meaning is brought [54].

\section{$\underline{\text { Results }}$}

The QUOROM (QUality Of Reporting Of Meta-analysis) diagram in Figure 1 demonstrates the outcome of the search. Fourteen studies were selected for the metasynthesis [55-68], providing a total of 326 participants (167 women, 159 men), aged 18-78 years. There was a large heterosexual bias, with only five participants identifying as gay (one woman, four men), two of which described having had relationships with others of both genders. Living arrangements included the family home, supported or staffed group homes, and cohabiting with partners 
(visited regularly by support staff). Table 1 describes the general characteristics of the studies. One study was excluded owing to a particularly poor quality score [69]. Though it is acknowledged that a study of poor quality may still contribute valuable findings and/or data [70], this particular article presented the same data used for another included [63], therefore little was lost.

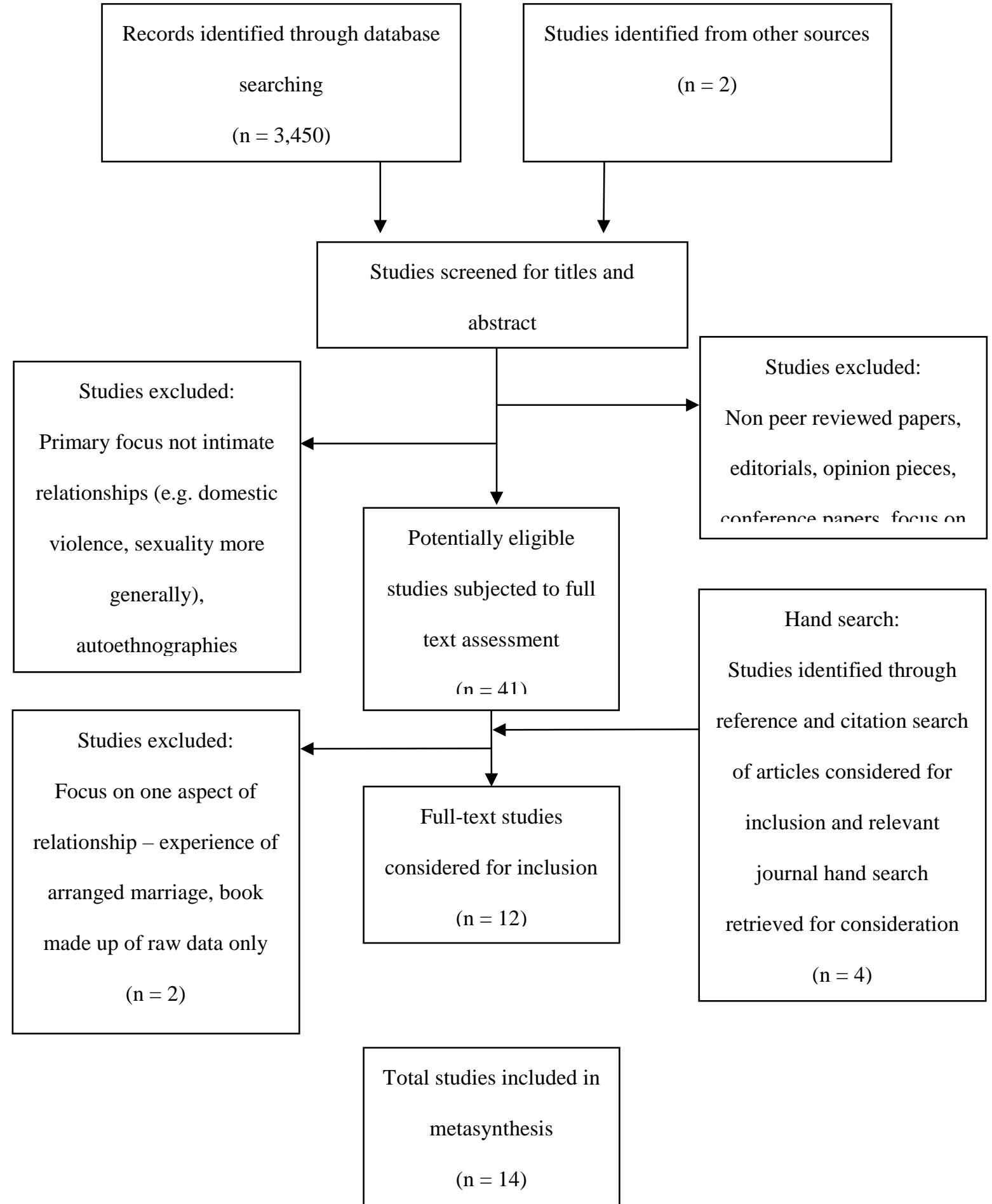

Fig. 1 Quorom disagram - flow diagram of the search and selection process 
Table 1: General characteristics, aims, methodology and key findings of studies included in the metasynthesis

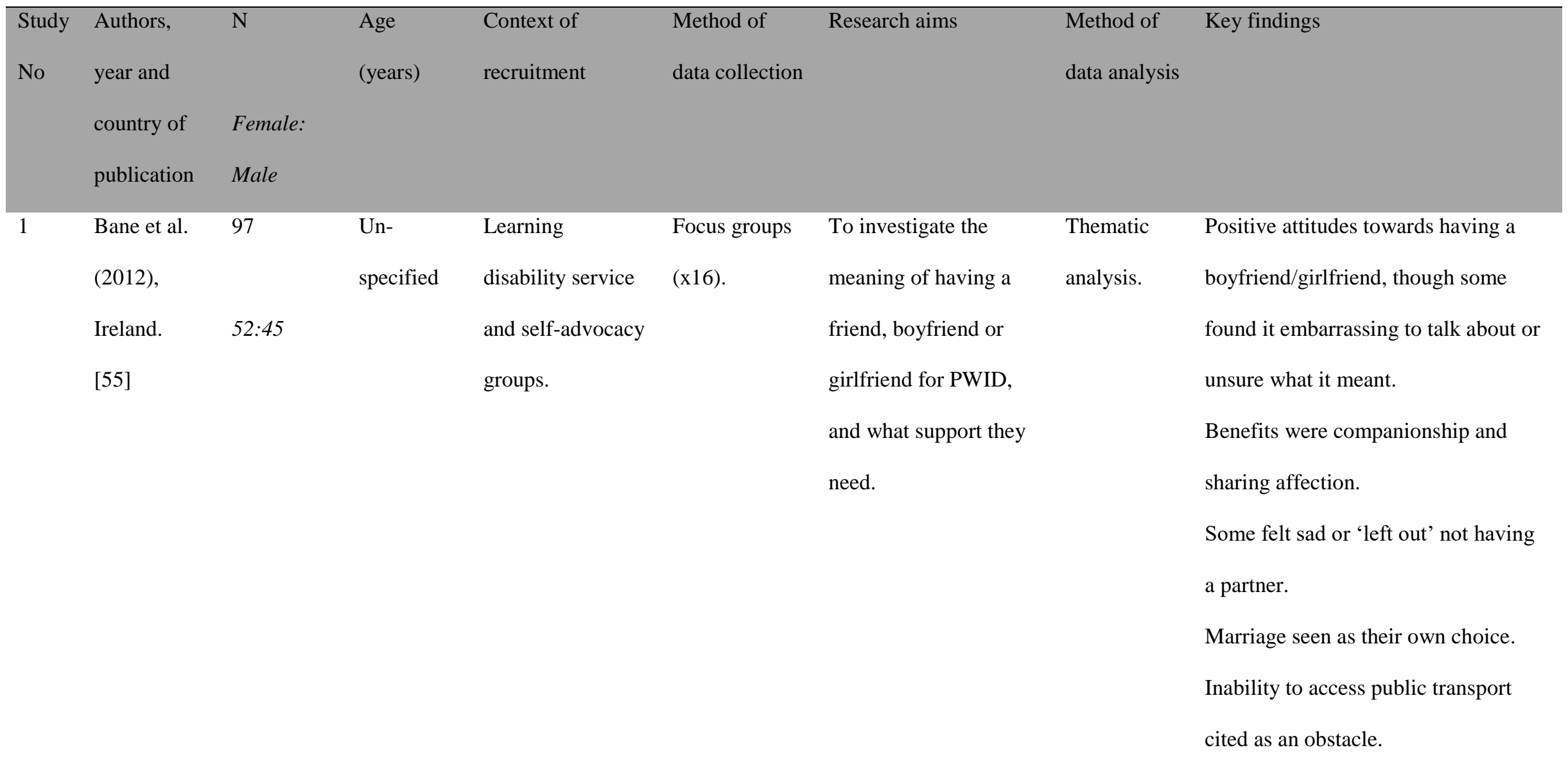




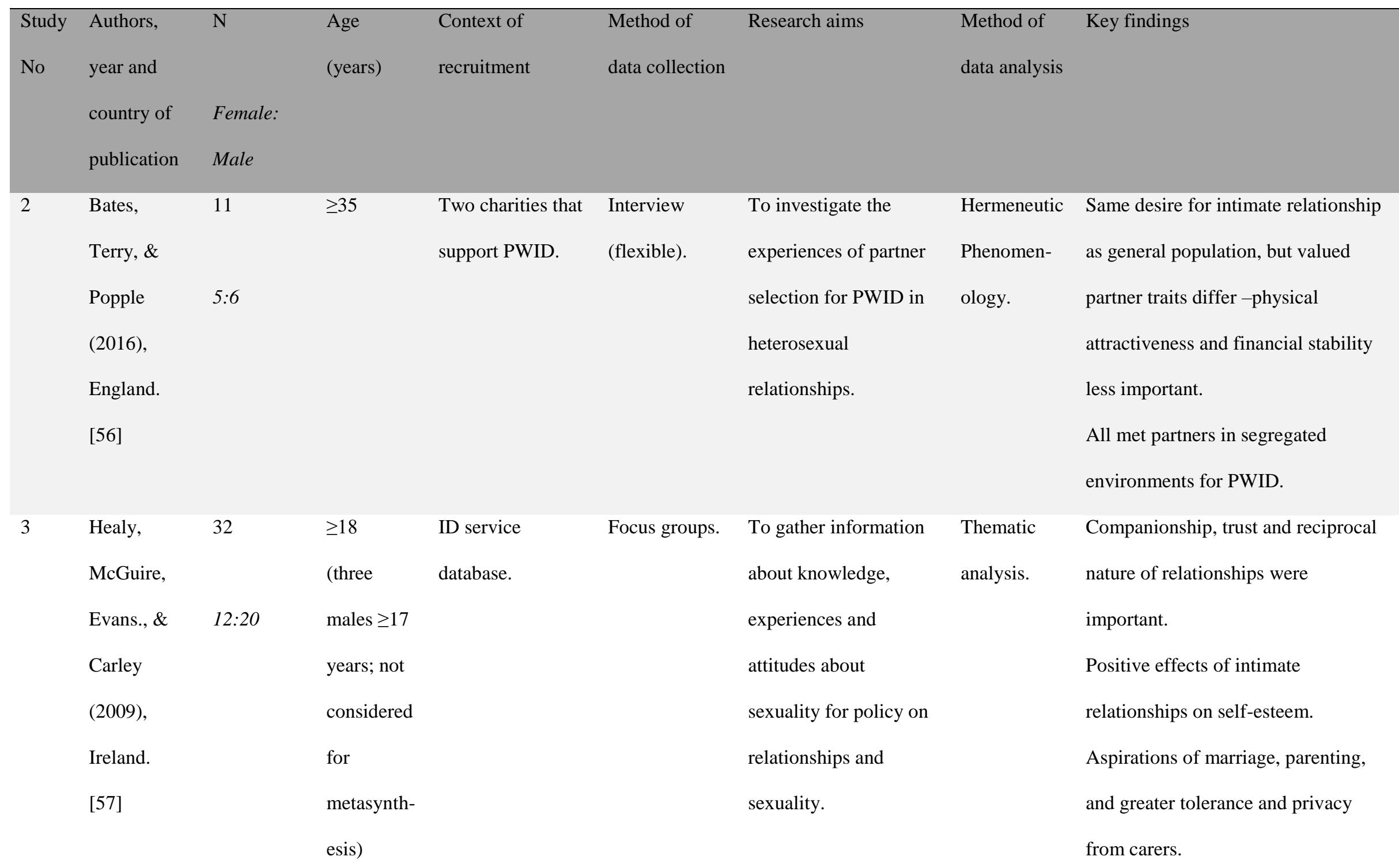




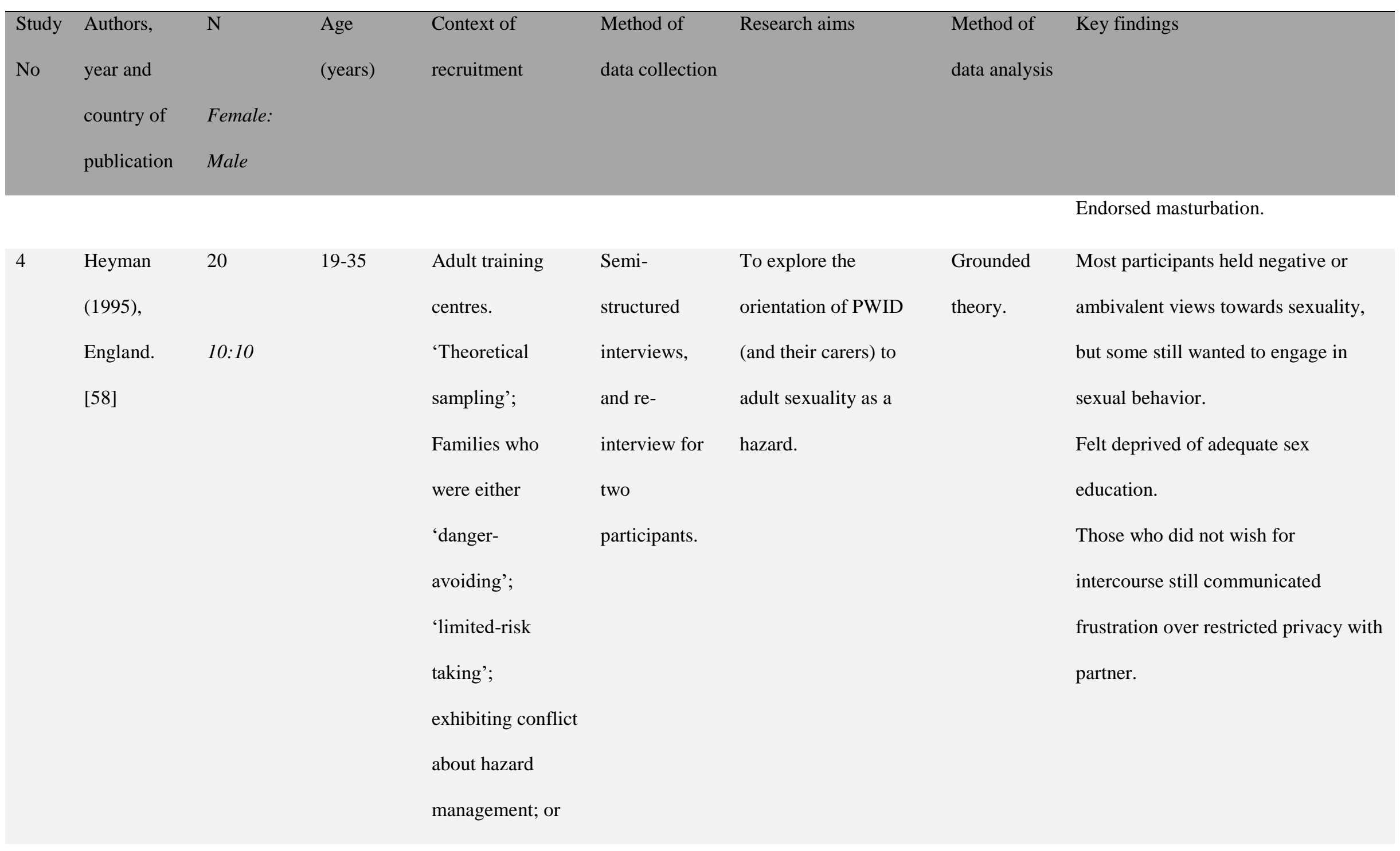




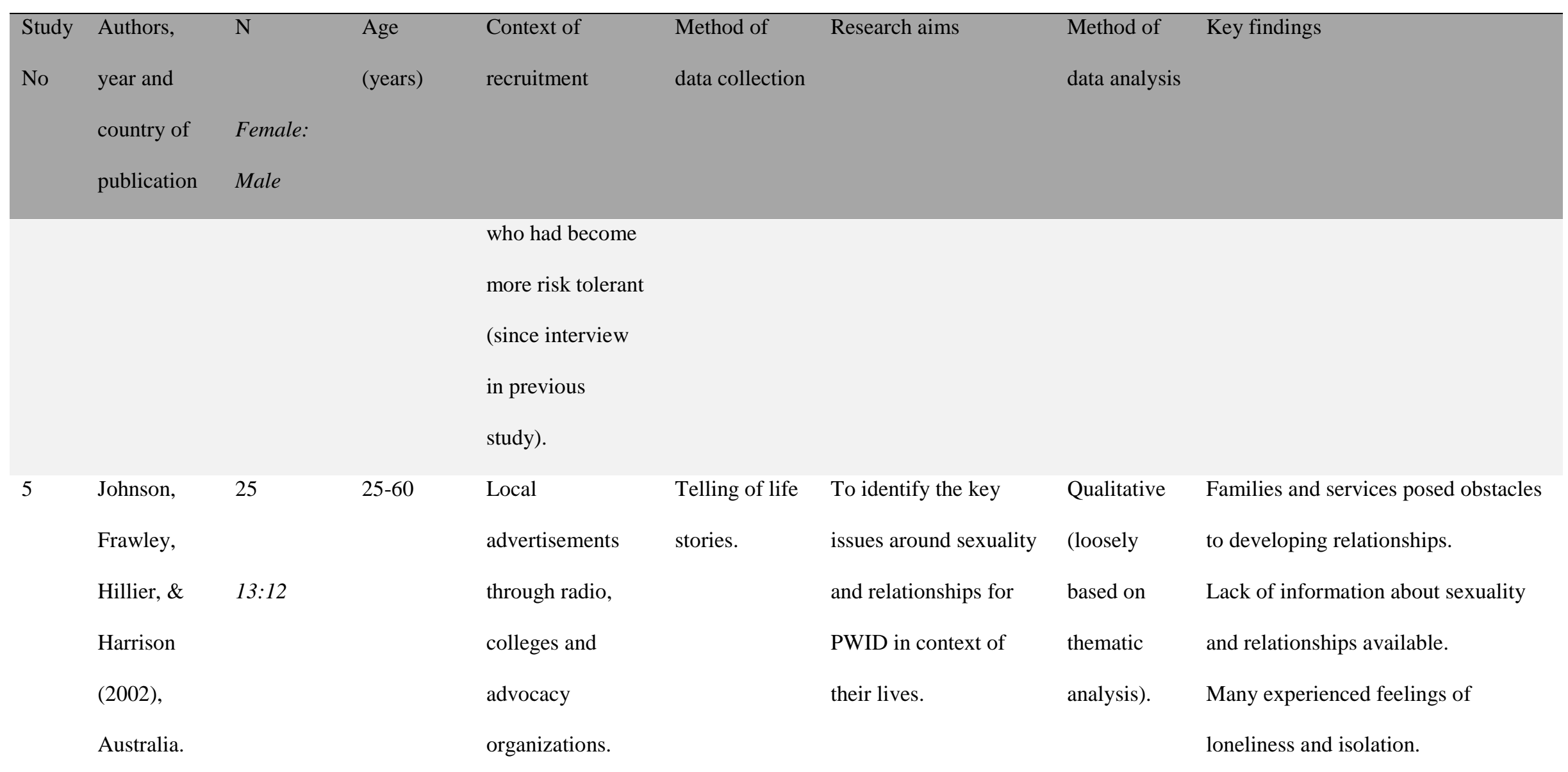




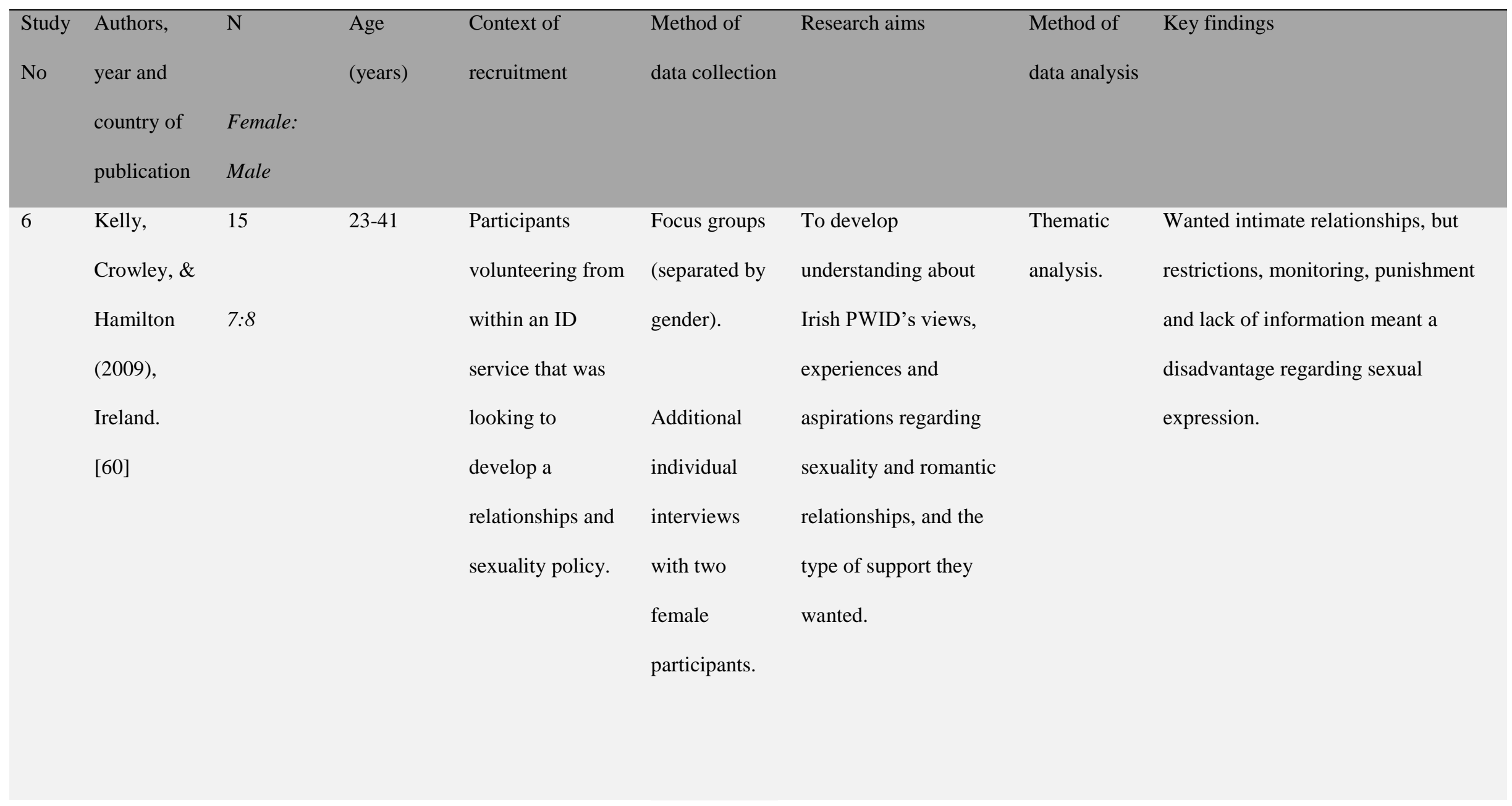




\begin{tabular}{|c|c|c|c|c|c|c|c|c|}
\hline $\begin{array}{l}\text { Study } \\
\text { No }\end{array}$ & $\begin{array}{l}\text { Authors, } \\
\text { year and } \\
\text { country of } \\
\text { publication }\end{array}$ & Female: & $\begin{array}{l}\text { Age } \\
\text { (years) }\end{array}$ & $\begin{array}{l}\text { Context of } \\
\text { recruitment }\end{array}$ & $\begin{array}{l}\text { Method of } \\
\text { data collection }\end{array}$ & Research aims & $\begin{array}{l}\text { Method of } \\
\text { data analysis }\end{array}$ & Key findings \\
\hline 7 & $\begin{array}{l}\text { Knox \& } \\
\text { Hickson } \\
\text { (2001), } \\
\text { Australia. } \\
{[61]}\end{array}$ & $2: 2$ & $26-58$ & $\begin{array}{l}\text { Two small } \\
\text { organizations } \\
\text { concerned with } \\
\text { supporting PWID. }\end{array}$ & $\begin{array}{l}\text { One-to-one } \\
\text { 'in-depth' } \\
\text { interviews } \\
\text { (unstructured). }\end{array}$ & $\begin{array}{l}\text { To explore the meaning } \\
\text { of 'close' friendships } \\
\text { held by PWID. }\end{array}$ & $\begin{array}{l}\text { Grounded } \\
\text { Theory. }\end{array}$ & $\begin{array}{l}\text { Distinction made between 'good } \\
\text { mate' and 'boyfriend/girlfriend'. } \\
\text { Boyfriend/girlfriend relationship more } \\
\text { changeable and would naturally } \\
\text { progress to marriage and children. } \\
\text { Restrictions and lack of privacy } \\
\text { precluded the development of intimate } \\
\text { relationships. }\end{array}$ \\
\hline 8 & $\begin{array}{l}\text { Lafferty, } \\
\text { McConkey, } \\
\text { \& Taggart } \\
\text { (2013), } \\
\text { Northern } \\
\text { Ireland. } \\
\text { [62] }\end{array}$ & $\begin{array}{l}16 \\
\text { (heterosex- } \\
\text { ual } \\
\text { couples) }\end{array}$ & $26-65$ & $\begin{array}{l}\text { Service providers } \\
\text { for PWID } \\
\text { throughout three } \\
\text { Health and Social } \\
\text { Services Board } \\
\text { areas. }\end{array}$ & $\begin{array}{l}\text { Interviews } \\
\text { with couples } \\
\text { and follow-up } \\
\text { one-to-one } \\
\text { interviews. }\end{array}$ & $\begin{array}{l}\text { Uncover the } \\
\text { experiences and nature } \\
\text { of couples with ID in a } \\
\text { relationship and the } \\
\text { meanings they ascribe } \\
\text { to them. }\end{array}$ & $\begin{array}{l}\text { Grounded } \\
\text { theory. }\end{array}$ & $\begin{array}{l}\text { Many benefits of being in a couple; } \\
\text { comradeship, sense of contentment, } \\
\text { reciprocity and commitment. }\end{array}$ \\
\hline
\end{tabular}




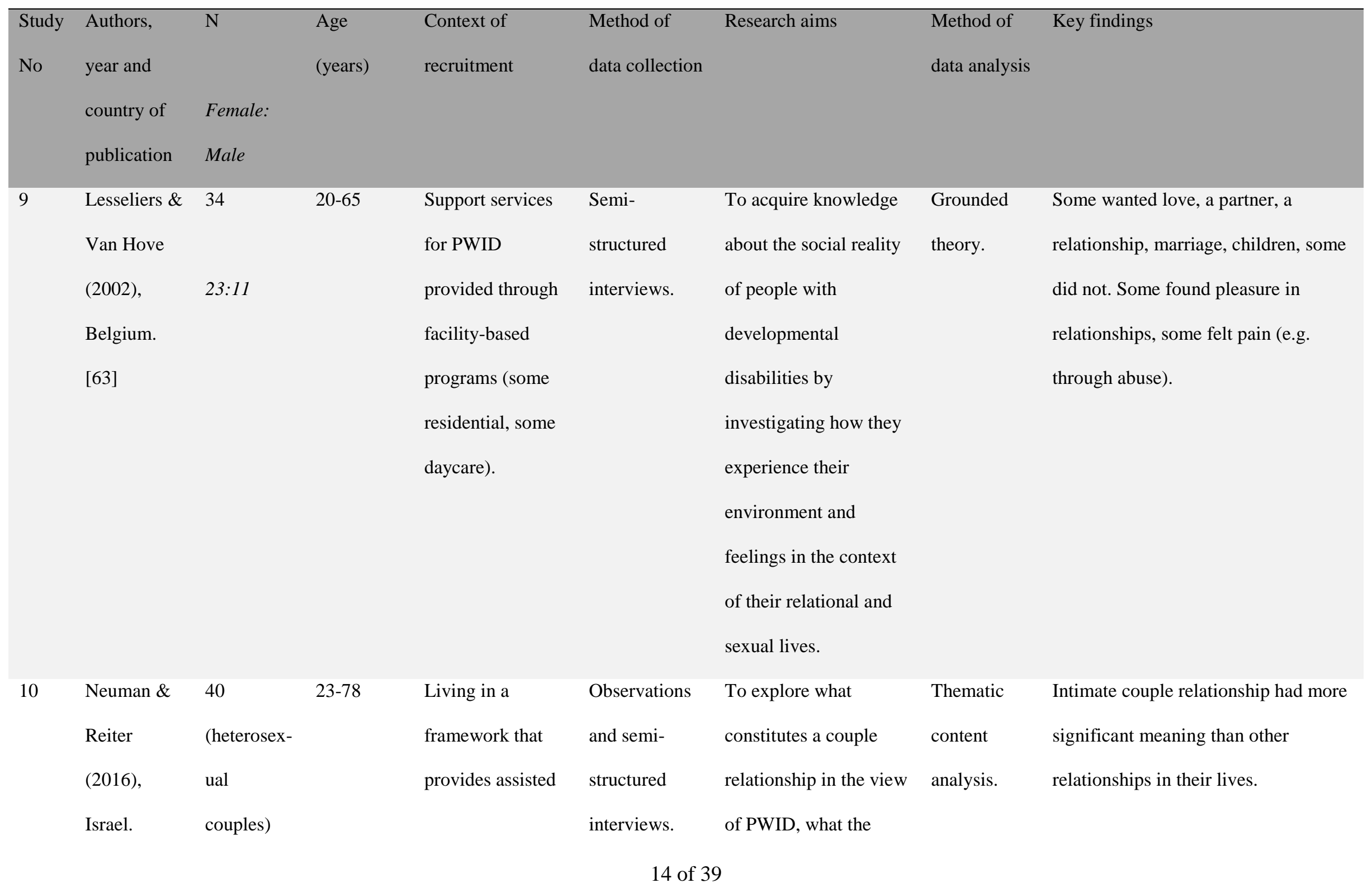




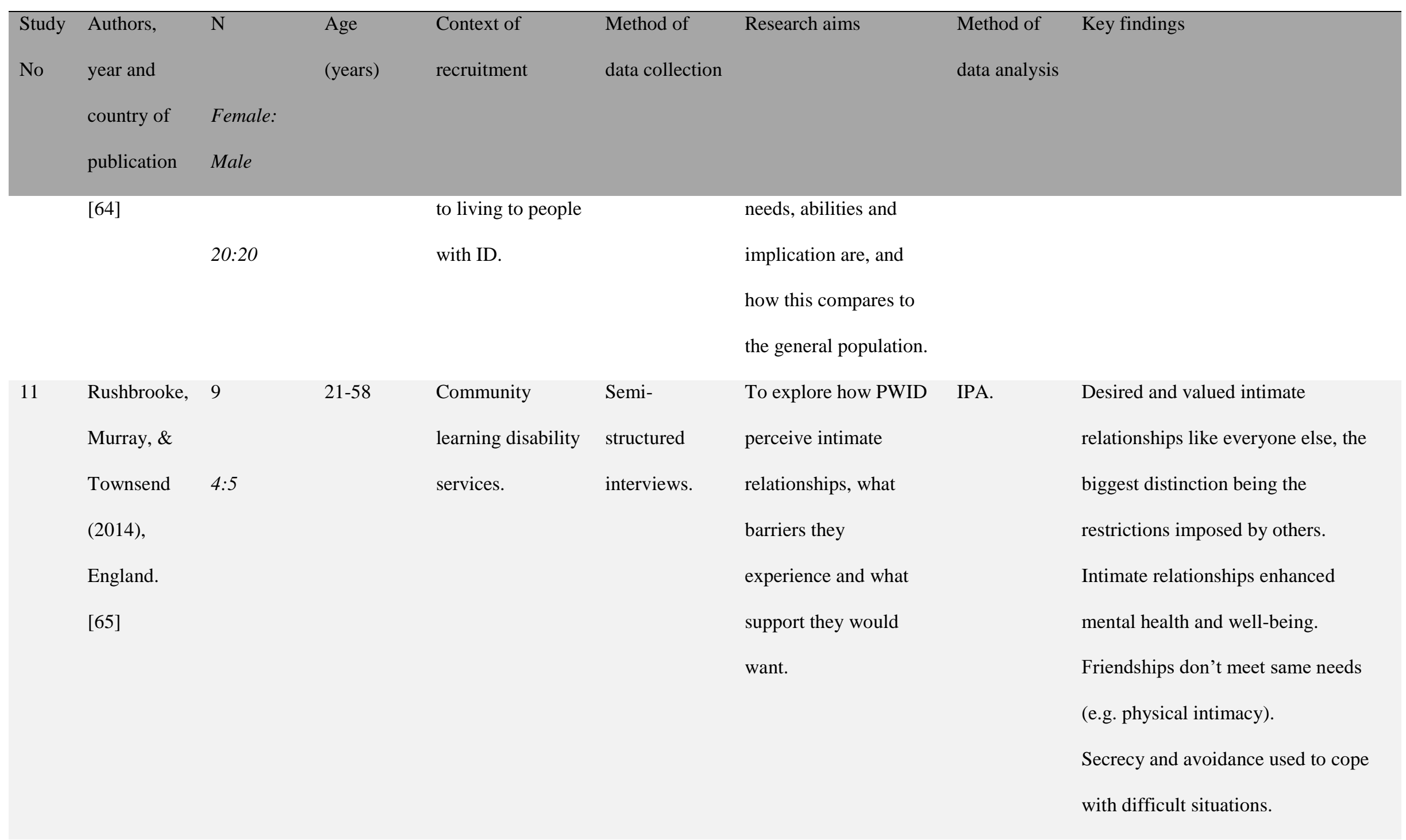




\begin{tabular}{llllllll}
\hline Study & Authors, & $\mathrm{N}$ & Age & Context of & Method of & Research aims & Method of \\
No & year and & & Key findings & data analysis \\
& country of & Female: & & & & \\
& publication & Male & & & & \\
& & & & &
\end{tabular}

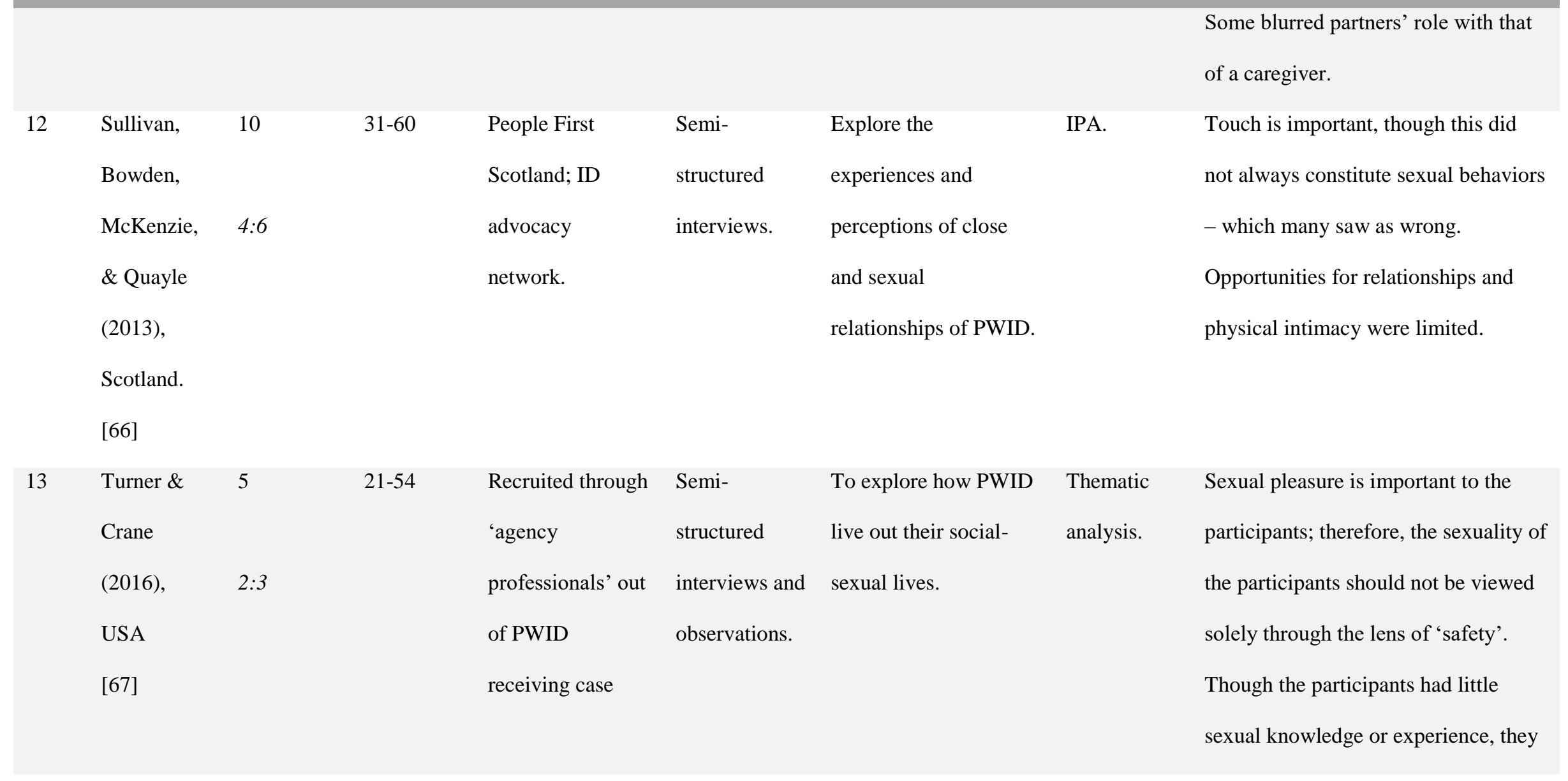




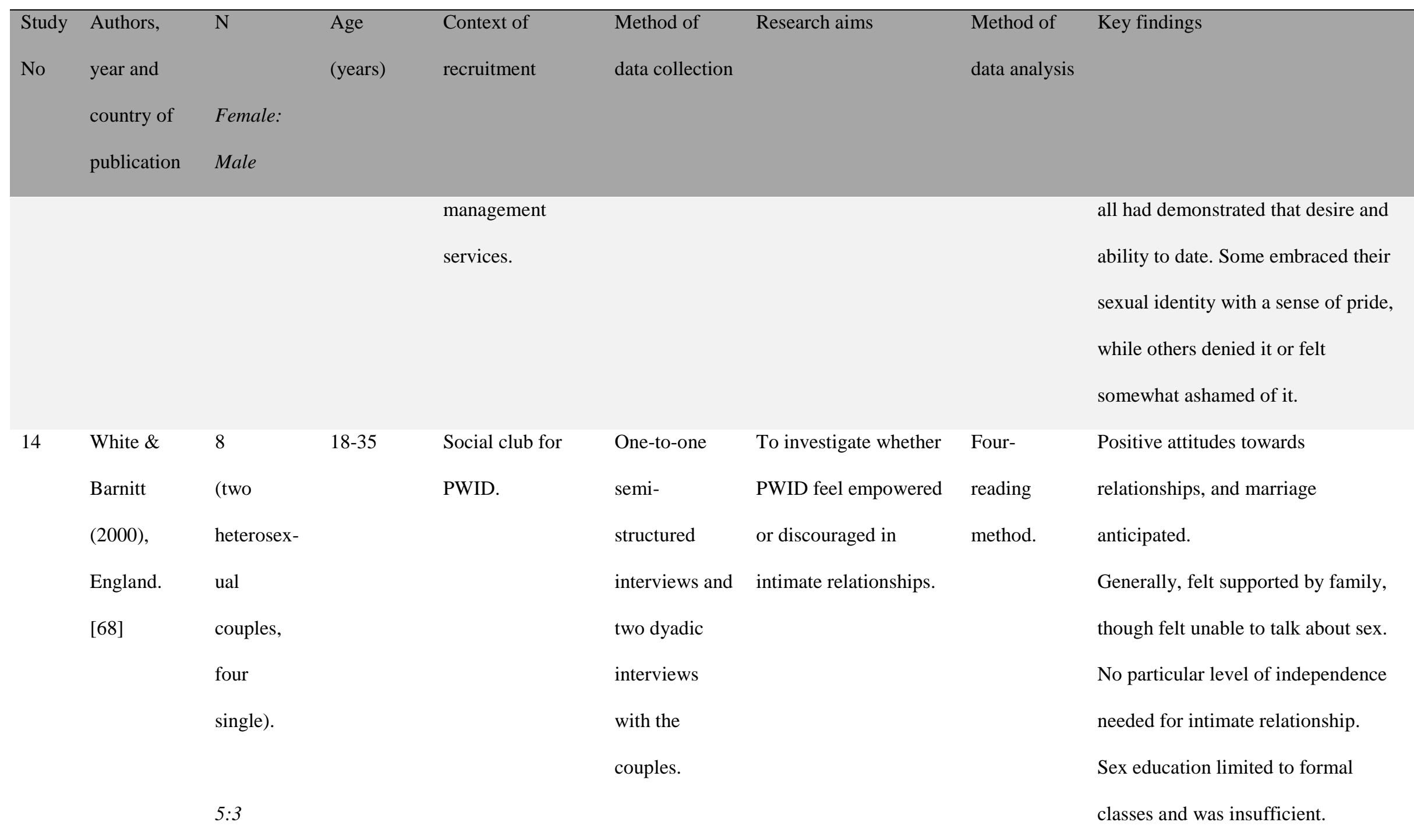




\section{Quality appraisal}

Table 2 shows the quality appraisal for each included paper. No study met all of the quality criteria. Only half of the studies $[56,62,63,65-68]$ met at least seven of the criteria, and the unmet criteria often made it difficult to assess the research process clearly.

Congruity between philosophical perspective and methodology utilized could not be established for a number of studies owing to a failure to identify the former $[55,57,59,62,65,60]$. Where the methodology used was not specified in two studies [55,59], correspondence with the authors established that thematic analysis had been used in both; the accessible format of the article, and the 'participatory action research' approach used, were the respective reasons the method of analysis had been omitted from the write up. Whether study five's methodology had been appropriate for the question remains unclear, since the method of data collection had also been unconventional. With the aims of most studies to focus on experiences, the wide range of ages within samples raised questions of heterogeneity, which would pose a risk of diluting the depth and credibility findings. This was a particular issue for those adopting a phenomenological approach $[56,65,66]$. The interpretations made in study six appeared further reaching than was warranted for a study with 15 participants (generalizing to 'PWID in Ireland'), and the extent to which the interpretation in study four [58] adhered to the inductive approach inherent in grounded theory was questionable, since the research was embedded in (and led by) the context of sexuality as hazardous for PWID.

All but four studies neglected to divulge the researchers' context in terms of beliefs and values $[55,63,67,68]$, which leaves the reader uninformed about any potential biases/perspectives in the development of research questions and how the study is conducted. Furthermore, though some reflexivity was described, very little consideration was offered as to how the context and perspectives of each researcher may have influenced the participants and the interpretation of the findings, or evidence of how this had been managed. All but two studies $[63,67]$ did this only partially or not at all, which is striking considering the many challenges that occur in conducting qualitative research with PWID, such as pressure to respond and inability to express feelings (Nind, 2008). A similarly alarming finding was that in nearly half of the studies there was no mention of ethical approval or consideration [57-61,63]. 
Table 2: Quality appraisal of each study based on an adapted version of the JBI checklist for qualitative research

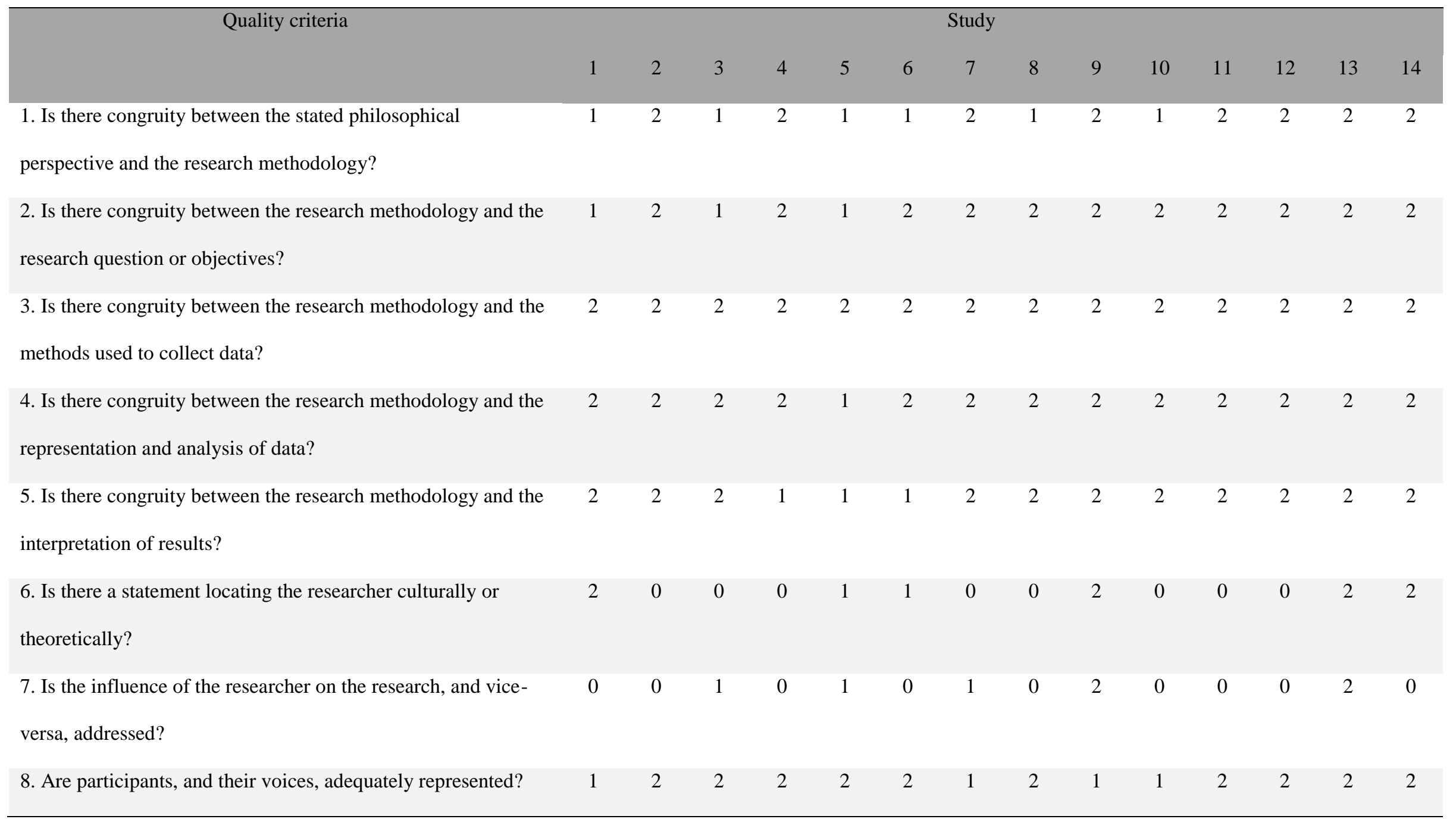


9. Is the research ethical according to current criteria or, for

2

20

0

0

$0 \quad 0$

20

$\begin{array}{lllll}2 & 2 & 2 & 2 & 2\end{array}$

recent studies, and is there evidence of ethical approval by an

appropriate body?

10. Do the conclusions drawn in the research report flow from

2

22

2

the analysis, or interpretation, of the data?

11. Did the recruitment strategy avoid biased selection

processes?

\section{Overall quality score}

16

141

A score of 0 indicates that either one or all elements of the criterion were not identified by the authors (e.g. for criterion one, the philosophical perspective, research

methodology, or both were not identified by the authors). A score of 1 indicates that there was insufficient detail provided by the authors regarding some or all of the elements to confirm that the criterion had been met (e.g. for criterion one, though the philosophical perspective had been stated, the description of the research methodology was insufficiently specific to determine whether it was appropriate). A score of 2 indicates that there was clear evidence that the criterion had been met. 
Participants' voices were well represented across almost all of the studies, but where this was absent or insufficient it was a result of a lack of transparency as to which participants were cited [55,63,64], less emphasis being placed on those not currently in a relationship [61], or a large sample [55] (97 participants represented through 18 citations of raw data), making it difficult for the reader to judge how closely the interpretations may fit the results.

Generally, the conclusions drawn from the research flowed logically from the interpretations of the data. However, in one study [65] there did appear to be an overgeneralization of the more positive views, for example, the conclusion that all PWID desire intimate relationships appeared to conflict with some of their findings around some participants' ambivalence on the matter . In another [59], the focus of the conclusion was the research process itself (participatory action research) rather than the qualitative findings. That many of the studies required participants to be identified by caregivers $[56,61-63,65]$ meant recruitment strategy was often a limitation. Recruitment will have been dependent on caregivers not only acknowledging or knowing about the relationships, but also presumably adjudging that potential participants' views would not reflect badly on them or the service. The range in quality amongst the studies appears largely down to a lack of clarity in reporting, however, all included studies can still be considered to provide findings of some value [70], especially since they provided a perspective of a population that has been severely lacking.

\section{Metasynthesis}

Three key themes were identified through the synthesis of the 14 studies, which were made up of multiple subthemes. The themes are outlined in table 3, with the studies contributing to each theme highlighted. Each theme and subtheme is expanded upon below, with the description supported by evidence from both second-order constructs and first-order constructs (raw data) cited in the individual studies.

\section{Theme One: The function and meaning of intimate relationships}

\section{Boyfriends/girlfriends are different to close friends}

For some, the distinction between intimate relationships and close friendship was how the former provides them with a means of physical closeness with another that the latter does not [60,61,63-65]: "A girlfriend would be 
Table 3: Cross-comparison of the third-order themes and subthemes with the studies included in the metasynthesis

\begin{tabular}{|c|c|c|c|c|c|c|c|c|c|c|c|c|c|c|}
\hline \multirow[b]{2}{*}{ Subtheme } & \multicolumn{14}{|c|}{ Study } \\
\hline & 1 & 2 & 3 & 4 & 5 & 6 & 7 & 8 & 9 & 10 & 11 & 12 & 13 & 14 \\
\hline The function and meaning of intimate relationships & $*$ & $*$ & $*$ & & $*$ & $*$ & $*$ & $*$ & $*$ & $*$ & $*$ & & $*$ & $*$ \\
\hline Boyfriends/girlfriends are different to close friends & $*$ & $*$ & $*$ & & $*$ & $*$ & $*$ & $*$ & $*$ & $*$ & $*$ & & & $*$ \\
\hline Why I want to be in an intimate relationship & $*$ & $*$ & $*$ & & $*$ & $*$ & $*$ & $*$ & $*$ & $*$ & $*$ & & $*$ & $*$ \\
\hline Physical intimacy & & & $*$ & $*$ & $*$ & $*$ & $*$ & $*$ & $*$ & $*$ & $*$ & $*$ & $*$ & $*$ \\
\hline External constraints and facilitators & $*$ & $*$ & $*$ & $*$ & $*$ & $*$ & $*$ & & $*$ & $*$ & $*$ & $*$ & $*$ & $*$ \\
\hline The attitudes of families & & & $*$ & $*$ & $*$ & & & & $*$ & & & $*$ & & $*$ \\
\hline Formal caregiver imposed prohibition & $*$ & $*$ & $*$ & & $*$ & $*$ & & & $*$ & $*$ & $*$ & $*$ & $*$ & $*$ \\
\hline Reprimand & & & & $*$ & & $*$ & & & $*$ & & $*$ & $*$ & & \\
\hline Support and facilitation & $*$ & & $*$ & & & $*$ & & & $*$ & & $*$ & & $*$ & $*$ \\
\hline Managing external constraints & $*$ & $*$ & $*$ & * & $*$ & $*$ & $*$ & $*$ & $*$ & $*$ & * & & * & $*$ \\
\hline Operating in secret & & & $*$ & * & $*$ & $*$ & $*$ & & $*$ & & $*$ & & $*$ & \\
\hline Marriage and commitment - looking to the future & $*$ & $*$ & $*$ & * & $*$ & & $*$ & $*$ & $*$ & $*$ & $*$ & & * & $*$ \\
\hline
\end{tabular}

*Indicates that the first and/or second order constructs within a study contributed to the corresponding third order theme or subtheme 
more suitable for me. Because I could...hold hands and...just enjoy ourselves like going to the pictures” [65, p. 534]; "being in love is healthy, it is laughing with each other, playing together, cuddling, and more of that." $[63$, p. 73]. Many alluded to the boyfriend/girlfriend relationship requiring a different sort of maintenance to others, mainly involving spending time doing activities alone together [55-57,61,64]. However, the distinction was less clear for some. The role of the boyfriend or girlfriend occasionally got blurred with that of paid carers [60,65]; two participants described a 'special friend', but both were referring to a member of staff whom they were attracted to [60]. Confusion over boundaries was demonstrated well by a participant speaking of a friend: "Well, I don't know what a boyfriend is. If I went out with Sean I wouldn't know what to do with a boyfriend" [55, p. 117].

\section{Why I want to be in an intimate relationship}

Positive views about intimate relationships were evident in all but two studies $[58,66]$. Most participants not in a relationship expressed a desire to be $[55,57,59,60,62,63,67]$, with the alleviation of feelings of loneliness often cited as a primary function. One participant highlighted this when she described life before finding her partner:

When you've a learning disability, it can be very lonely. You end up just sitting in the house and wandering about on your own and all and you ... feel as if the whole world is coming down on top of you and [you] feel like suicide ... I would have stayed in bed all day, never bothered getting up. [62, p. 1080]

Companionship [56,57,60,62,64,65], being supported [56,60,64,65,67], loved and cared for $[55,56,64,65,67,68]$ also featured heavily as things that participants perceived that intimate relationships would bring to their lives, which was conceptualized by one study [67] as coming out of individuals 'choosing to be known' by another person. A minority reported not wishing to have a partner; three having been hurt in previous relationships, adopted 'a lifestyle of transitory relationships' [59, p. 7], whilst another stated that she preferred to stay at home and was a 'mummy's pet' [60]. Not wanting to be in a relationship was generally associated with previous experience of physically $[62,64,65]$ and emotionally $[59,68]$ abusive relationships. 


\section{Physical Intimacy}

Though seen as an important part of an intimate relationship for some, it appeared that for just as many, physical affection, especially that considered overtly sexual, was not integral for an intimate relationship. Some participants, despite being in intimate relationships, rejected physical intimacy outright as 'dirty', 'yucky' $[58,63]$, shameful, wrong or dangerous $[58,60,63,65-67]$, or viewed it as an 'affair' (seeming to link it to secret and immoral portrayals seen depicted on television [60]). The disapproval of caregivers was the most prevalent fear about physical intimacy [58,63,65,66]: "Interviewer: Do you have a sexual relationship [with girlfriend]? Adult: No. Interviewer: Why not? Adult: I think it is wrong. I am not allowed" [58, p. 148]. However, many expressed a desire to engage in at least some form of physical contact, ranging from kissing, cuddling or caressing $[55,63,64,67]$, to full intercourse $[58,63,65,67]$. The conflict between desire and the negative message provided by families, staff and sometimes peers/partners led to ambivalent views about physical intimacy for some, as encapsulated well here:

Interviewer: Would you like a sexual relationship ever?

Adult: ... It's like something inside me. One half says yes, and one half says no... When you are in love with somebody, you can have a good relationship by being friends. If you are having sex, you are taking risks.

Interviewer: Do you mean having babies?

Adult: No, AIDS or something like that. If I had sex with [girlfriend] on holiday she would come back, and her mum would say to her if she had enjoyed herself with me, and she would say that she had sex, and she would be mad and get on the phone and play hell with me. [58, p. 150]

Direct experiences of physical intimacy with partners were referenced in all but four studies $[55,56,61,68]$.

Some participants indicated that they do not engage in sexual intercourse, but in other behaviors that are equally important to maintaining the intimate relationship, e.g. hugging and kissing [66]:

I felt closer to William than I did, than I did to Ben [...] because he used to, he used, he used to put his two arms around me [...] instead of just one it was two [...] It made me feel more secure. [66, p. 3462] 
Negative experiences of physical intimacy all related to sexualized behavior $[57,59,63,64,66]$. For some this was getting 'caught red handed' having sex [57], for others, unfulfilling or upsetting experiences arose with their partners; agreeing to painful sexual acts [63], engaging for a partner's benefit, or feeling pressured by the actions of their partner $[63,64]$. Thirty-four participants $(10 \%$ of total $n)$ across four studies $[56,59,63,66]$ directly reported having been the victim of sexual assault or rape, most of those participants reporting a subsequent aversion to intimacy of a sexual nature, but not more generally to intimate relationships.

All but four studies $[55,56,62,64]$ made reference to understanding of physical intimacy and where this knowledge came from. Though some had been made aware of the mechanics of sex $[59,60,63,66]$, ideas around pleasure and human connectedness were generally omitted [60,66,67]. Informal information from caregivers was generally delivered ad hoc and at their discretion (e.g. when risk was feared), which in some cases painted a rather negative picture:

Grace (interviewer): Elizabeth, have you ever had a sex education class?

Elizabeth: No I never went (. . .) only mammy told me. (...)

Grace: And what kind of things did she tell you about?

Elizabeth: About the development. About people touching me (. . .) Harassment. [60, p. 310]

Formal sex education was very rarely mentioned $[58,59,63,68]$, with some who had experienced it describing it as 'embarrassing' and 'irrelevant' [59]. Knowledge was often limited and/or partial; understanding of masturbation $[57,63]$, contraception $[57,65,67]$ and consent $[57,63]$ was rare, and rudimentary at best. Those wanting further information were forced to acquire it opportunistically through television, magazines or observations of others $[57,58,60,63,67]$, and for some this knowledge appeared to directly influence how they engaged with partners - one participant explaining that he did "the same thing that they do in the porno - it was my first time. Like put their penis inside a vagina, and uh, put it in the mouth and, uh, put it in their butt." [67, p. 687-8]. 


\section{Theme Two: External constraints and facilitators}

The attitudes of families

Examples were provided in six studies $[57-59,63,66,68]$ of family members' disapproval of participants' intimate relationships, especially if there was a sexual element to them. For some this was overtly expressed by preventing partners staying over (or vice versa) [58,65-68]:

My friend...I said to my mother, um, I'm going to invite her to stay with at my house and she turned around and said well if you're going to do that don't come back to the house...I phoned her mother to say that, um, I'll have to ask her to leave because my mother says if I'd if I have her in the house then she's going to disown me. [66, p. 3460]

For others this was less explicit; granted permission to stay over with his partner, the sister of one participant's partner put a single bed and a camp bed in the room to replace the double [66]. This act conveys a clear message about how the family member wishes the couple to behave. Many felt unable to talk to parents about their relationships, anticipating disapproval $[58,66,68]$.

\section{Formal caregiver imposed prohibition}

Restrictions and rules implemented by the various services accessed appeared in all but three studies [58,61,62], such as 'it's ok to have a friend but not a boyfriend/girlfriend' [55,60] and 'they don't let people stay overnight' [66]. Some agreed on a need for rules [57,63], but found those enforced excessive and neglectful of their needs: “I do really think that we don't matter because we don't have any much of a life anyway" [57, p. 910]. There was a lack of clarity over what the rules actually were $[57,59,60,63,65,68]$. Confusion was maintained by the inconsistent way rules were enforced, for example:

Before we shared our room, a staff member knocked on the door and found us together. She said 'Get into your own bed'. I didn't like her that much doin' that. Because we're two adults and she should have let us do it. We didn't like it, so we left one night and we had sex somewhere. When we came back they had a talk to us and they said 'You can move into a room together'. [59, p. 7] 
Some resisted the restrictions being imposed on them [57,60,67,68]: "I said I'm not giving in to you . . . they have to give up because they get tired" [57, p. 908] and demonstrated a sense of pride in their right to a sexual identity. Others however, reported feeling defeated by the restrictions, and seeming reluctant to describe themselves a sexual or romantic beings, resigned themselves to being powerless to fight for the opportunity to obtain an intimate relationship, and so ceased trying [60,63,67].

\section{Reprimand}

Direct reprimand was identified in five studies $[58,60,63,65,66]$. Examples included being told off for holding hands [65] and kissing [60], detention [66] or having it recorded on their file [58] when caught having sex, and even being punished for waiting around for a peer: "Ow, they made me remember that day, we were punished the whole day although we did nothing wrong" [63, p. 75]. This led to fear over the repercussions for being physically intimate $[58,63,65,66]$. Many participants avoided speaking of their desires to staff, parents or even partners $[58,63,65,66]$.

\section{Support and facilitation}

Though caregivers supporting intimate relationships was recurrent across first order constructs in six studies $[55,57,60,63,65,68]$, incidence was minimal. Some said caregivers had an important role to play at difficult times [55,65]: “The good times was when I was having a good patch, when like, I'd basically ignored him and stuff. And I was getting all the support I needed" [65, p. 537], and when meeting with a new partner to make sure they are 'trustworthy' [65]. However, refutational data highlighted that formal staff did not offer counselling at particularly confusing times [63], and that staff are 'afraid' to give socio-sexual advice [57]. This was associated with confusion and 'heartache' as participants struggled to understand and process relationship conflict [63] and breakdown [65]. Two participants in one study [60] reported staff being supportive in their relationships, however, in contrast some had been put under pressure to end relationships:

Grace (interviewer): You said Elizabeth that you gave a guy a kiss (...) Was he your boyfriend?

Elizabeth: He was, yeah, (. . .) we broke up years ago.

Grace: Ahh (sympathetically)

Elizabeth: Yeah. And we had to be friends. 
Grace: (...) You had to be friends?

Elizabeth: Yeah.

Grace: Why?

Elizabeth: Because it's the rule of the staff. [60, p. 313]

Failure to support the maintenance of intimate relationships at a service level was discussed in three studies in terms of the feared, or enforced separation or move of a partner to another facility [56,63,64]: "I'm scared of you (the caregiver), afraid that you will not let us live together. Do not take him away from me" [64, p. 5].

\section{Theme Three: Managing external constraints}

\section{Operating in secret}

Recurrently within seven studies [57-61,63,65] participants stated they were never alone and were constantly monitored, which was overbearing, as encapsulated by one participant:

Having support there all the time we couldn't feel like we could do things what normal people would do in a relationship. Like kiss, cuddle, hold hands...And we felt like that we didn't have space, and it felt like quite intimidating for me, having staff there all the time. [65, p. 538]

The lack of privacy afforded forced many participants into engaging in acts of physical intimacy in secret [5760,65]. One participant explained how he achieves this secrecy: “At the centre we are not allowed to kiss and cuddle, but we still sneak one in when nobody is looking" [58, p. 148]. Surreptitious behavior functioned to avoid the disapproval of others [58,60,65], prevent further prohibition or punishment $[57,59]$, but also to protect others from upset such as parents [65]. Acting in secret made individuals vulnerable, since the acts tended to be carried out in public places, in a hurried manner devoid of appropriate care (e.g. unsafe sex) [59] and 'divorced from interpersonal intimacy' [58].

\section{Marriage and commitment - looking to the future}

Thoughts about the future featured in all but two of the studies $[60,66]$, a desire to marry evident in most. Finding an intimate relationship and/or marriage was linked in a number of studies to some form of perceived 
control $[62,63]$ or progression in life $[56,57,61-64]$. For some participants it also meant status, and acceptance that they were "just like other people and special to someone" [56, p. 7], and a means of moving towards a 'normal' identity, which for some was associated with a marked sense of pride [67]. However, an actual [58,59] or presumed $[57,63]$ outright prohibition of marriage was described by some, which could be particularly upsetting; one participant described how her sibling was "married you see and then I feel kind of sad cause that I can't you see. I mean I think it's not fair, I think I should be happy as well” [57, p. 910].

Planning for the future appeared more concrete for those already in a relationship, with some idealistic views portrayed: "Well, that's what we want (to get married), you know, a wee house, a wee dog and Michelle wants a bird" [62, p. 1083]. However, for planning for the future to begin, and a better life worked towards, finding a relationship was seen as an integral first step.

\section{Line of argument synthesis}

Most participants expressed a desire to have an intimate relationship, citing that such relationships can function to alleviate loneliness, feel supported and cared for, and feel physically close to someone. Though a desire for physical intimacy was mentioned by some, this was not universal, and when it was present it did not necessarily constitute sexual intercourse, with other forms of physical affection such as hugging and holding hands described as important to maintaining intimate relationships.

Whether physical intimacy was desired within intimate relationships or not, participants across all studies felt that varying degrees of constraint were being put on them in terms of being able (or allowed) to engage in intimate relationships and to what extent. The prohibition of relationships experienced ranged from the implicit (e.g. disapproval) to the overtly explicit, in terms of the enforcing of sweeping rules, and ranged from a total denial of intimate relationships, to condoning intimacy up to a point, for example, hugging and kissing allowed but nudity and intercourse not. In response, two main approaches were adopted to overcoming the constraints. The first was to pursue an ambition to get married. The participants appeared to feel that by their relationships being acknowledged and accepted they would be able to progress in their life and take steps towards a 'normal' identity rather than one of disability. The second was to fulfil the relationship, or at least certain parts of it, in secret. This was particularly the case when some level of physical intimacy was sought. When this involved sexual behavior it often led to PWID engaging in risky practice such as unsafe sex and/or doing so in public. 
Upsetting or risk-laden romantic experiences appear to also in part be a consequence of poor sexual or relationship knowledge owing to insufficient education on the matter and an aversion to discussing such matters with family, formal caregivers or even partners, for fear of disapproval. In addition, the common absence of conceptualisations of pleasure in discourse around sex and relationships for PWID perpetuates this poor understanding and potentially leads some to engage in such behaviors as another means of pursuing the 'normal' identity, which can result in upsetting rather than enjoyable experiences. Knowledge was sought from other sources by some, such as TV, film and magazines, which in turn was associated with sex and intimate relationships being understood as dangerous and inappropriate (e.g. labelling them as 'affairs'). Though some lead a spirited individual rebellion against the constraints placed on them, sadly, many appear to not have the understanding or the fight to do so.

\section{$\underline{\text { Discussion }}$}

Varying levels of methodological and reporting quality were identified across the studies, with none meeting all criteria. The collection and analysis of data was generally appropriate, using a suitable methodology to answer the question posed. However, almost half of the studies failed to mention ethical approval, which is a major shortcoming given the studies entailed discussing sensitive topics with vulnerable people. Ethical approval may have been obtained, and perhaps was a precondition of publication, but this cannot be assumed if not stated. Ethical approval must be explicitly addressed in studies, not only for transparency of the research process, but to set a clear standard for the way in which PWID should be treated. The absence of statements regarding the researchers' context culturally or theoretically was conspicuous, especially considering high levels of interpretation needed for data that often lacked depth. Furthermore, when recruiting participants, researchers asked staff to identify participants, meaning they would have to be aware of and acknowledge the individual's intimate relationship(s), and potentially, perceive that their input would not reflect badly on the care being given. Consequently, potential biases in the development of research questions, sampling, and the interpretation meant the trustworthiness of many studies was difficult to determine.

Since previous research suggests that PWID benefit from being in intimate relationships [24,26-31], the finding that almost all participants desired one was unsurprising. Participants emphasized the loneliness of 'having nobody', and conceptualized intimate relationships as multi-dimensional, with descriptions of 'companionship' and being 'loved' and 'cared for' featuring heavily across the studies. Physical and sexual intimacy provided 
only one aspect of intimate relationships, and one not desired by all. This is at odds with the portrayal of intimate relationships in PWID in previous literature being inevitably associated with sexual behavior and the perceived risk associated with it $[11,14]$.

Across the reviewed studies, PWID experienced restricted opportunities to develop intimate relationships both on an explicit and implicit level. From a developmental perspective, these restrictions demonstrate a denial of the social and emotional support PWID require to move through 'normal' developmental stages [38,39]; a failure to equip them with the skills and understanding needed to develop intimate relationships. From a perspective of considering the rights of PWID, the restrictions seem at odds with national policy $[9,10]$. The level of restriction experienced varied across studies, for example, some participants were forced to end relationships, while for others the relationship was condoned but privacy together was not. The messages being delivered to PWID through these restrictions, were internalized to varying degrees, as has been exhibited in previous literature [18-20]. The extent to which the influence of others through these various channels was internalized can be conceptualized as being on a continuum. At one end, those who appeared to accept that intimate relationships were not acceptable for them, at the other, the few cases explicitly rejecting the restrictions. The majority of the participants appeared to hold the middle ground and harbour an ambivalence or cognitive dissonance [71] between wanting to have an intimate relationship, and believing that they are wrong or risky. This appears to mirror the ambivalence harboured by those supporting PWID about enabling intimate relationships and protecting them from harm $[11,14]$.

Confusion over relationships, seemingly maintained by the partial/biased information afforded to them, saw a lack of clarity about boundaries, poor understanding of physical intimacy in the context of relationships, and numerous reports of negative relationship and sexual experiences. In spite of this, intimate relationships were generally still desired. Measures taken by PWID to fulfil their needs, most notably to act in secret, often put them at greater risk, i.e. acting in unsafe environments, with an unnecessarily poor understanding of what they are doing. This suggests that those caring for PWID limiting access to intimate relationships in an attempt to protect them from harm might inadvertently increase risk. The prevalent ambition of marriage can here possibly also be understood as PWID's attempt to exert some control over unmet developmental needs regarding relationships in the absence of sufficient support to do so. This fits with past findings that PWID strive for a 'normal' identity by trying to achieve goals that align them with this [17], as marriage was generally seen as a 
marker for life progression, and would equate to an intimate relationship being accepted by others, a perceived means of resolving the felt dissonance.

Intimate relationships are not inextricably linked to sexual behavior for PWID. Our findings suggest that maintaining this purported link leads to denial of the knowledge, skills, and privacy to access the enhanced quality of life an intimate relationship could bring, presumably through the implied connection to risk. Therefore, it is important that future research and education for PWID and their carers acknowledge the distinction between sexual behaviors and intimate relationships and portray the overlap between them as possible but not inevitable. Acquisition of new information offers a means of alleviating cognitive dissonance [71]. Providing new information here, in terms of providing insight into how intimate relationships for PWID are not inextricably linked to sexual behavior and /or risk could act to relieve some of the ambivalence carers appear to feel around the intimate relationships of those they care for - relationships that can ultimately bring much happiness, pleasure and satisfaction.

There are some limitations to the metasynthesis. As can be seen from the citations, the raw data was not overly rich, meaning that a high level of interpretation was sometimes evident in second order themes. Insufficient statements regarding researchers' context (and therefore potential biases) meant that the distance being put between first and third order constructs through the triple hermeneutic was at times difficult to determine. A prevalent inclusion criterion across the studies was the ability to clearly communicate experiences verbally, therefore the more severely disabled were absent in the primary studies. Though including those with expressive language difficulties poses an obstacle in research this is not insurmountable [72]. Their absence leaves a considerable section of the ID population whose views have not been represented and therefore little is known about their relationship needs. Future research should remedy this.

Metasynthesis as a process carries dangers of imprecision, with the aggregating of multiple equivocal qualitative findings potentially 'thinning out' the human experiences presented in the original studies [70]. Consideration of this was pertinent to the current metasynthesis, with data being collected, analysed and presented in a multitude of ways across the studies (including accessible formatting). However, the strong recurrence of themes across the studies reviewed here implies that the synthesis is valid [73], as does the fit of the findings within existing literature [74]. 
To conclude, the findings of the metasynthesis do not necessarily reveal things that were not already being suggested, but now that PWID have been asked, policy, practice and sex education no longer needs to be based on assumptions. A delineation of intimate relationships and sexual behavior in future research provides an opportunity to move away from the focus on risk and highlight the benefits of the former that PWID are being denied through blanket restrictions and reprimands. Greater emphasis on quality in this research, in particular transparency regarding ethical procedures, is essential.

Word count: 6648 


\section{$\underline{\text { References }}$}

1. Drew, C.J., Hardman, M.L.: Mental Retardation: A Lifespan Approach to People with Intellectual Disabilities. Prentice Hall, New Jersey (2004)

2. McCarthy, M.: Sexuality and Women with Learning Disabilities. Jessica Kingsley Publishers, London (1999)

3. McRuer, R., Mollow, A.: Introduction. In: McRuer, R., Mollow, A. (eds.) Sex and Disability. pp. 1-34. Duke University Press, Durham (2012)

4. Szollos, A.A., McCabe, M.P.: The sexuality of people with mild intellectual disability: Perceptions of clients and caregivers. Australia and New Zealand Journal of Developmental Disabilities 20(3), 205-222 (1995)

5. Wolfensberger, W.: The Principle of Normalisation. National Institute on Mental Retardation, Toronto (1972)

6. Wolfensberger, W.: Social role valorization: A proposed new term for the principle of normalization. Ment. Retard. 21(6), 234 (1983)

7. Thompson, J.R., Hughes, C., Schalock, R.L., Silverman, W., Tassé, M.J., Bryant, B., Craig, E.M., Campbell, E.M.: Integrating supports in assessment and planning. Ment. Retard. 40(5), 390-405 (2002)

8. United Nations: Universal Convention on the Rights of Persons with Disabilities. United Nations, New York (2006)

9. Department of Health: Valuing People: A New Strategy for Learning Disability for the 21st Century. The Stationery Office, London (2001)

10. Department of Health: Valuing People Now: A Three-Year Strategy for People with Learning Disabilities. The Stationery Office, London (2009)

11. Rushbrooke, E., Murray, C.D., Townsend, S.: What difficulties are experienced by caregivers in relation to the sexuality of people with intellectual disabilities? A qualitative meta-synthesis. Res. Dev. Disab. 35(4), 871-886 (2014)

12. Evans, D., McGuire, B., Healy, E., Carley, S.: Sexuality and personal relationships for people with an intellectual disability. Part II: staff and family carer perspectives. J. Intell. Disab. Res. 53(11), 913-921 (2009)

13. Futcher, S.: Attitudes to sexuality of patients with learning disabilities: a review. British Journal of Nursing 20(1) (2011)

14. Löfgren-Mårtenson, L.: "May I?” About sexuality and love in the new generation with intellectual disabilities. Sex. Disabil. 22(3), 197-207 (2004) 
15. Ryan, D., McConkey, R.: Staff attitudes to sexuality and people with intellectual disabilities. The Irish Journal of Psychology 21(1-2), 88-97 (2000)

16. Brown, H.: 'An ordinary sexual life?': A review of the normalisation principle as it applies to the sexual options of people with learning disabilities. Disabil. Soc. 9(2), 123-144 (1994)

17. Wilkinson, V.J., Theodore, K., Raczka, R.: ‘As normal as possible’: sexual identity development in people with intellectual disabilities transitioning to adulthood. Sex. Disabil. 33(1), 93-105 (2015)

18. Bernert, D.J.: Sexuality and disability in the lives of women with intellectual disabilities. Sex. Disabil. 29(2), 129-141 (2011)

19. Cuskelly, M., Bryde, R.: Attitudes towards the sexuality of adults with an intellectual disability: parents, support staff, and a community sample. J. Intellect. Dev. Dis. 29(3), 255-264 (2004)

20. Murphy, G.H., O'Callaghan, A.: Capacity of adults with intellectual disabilities to consent to sexual relationships. Psychol. Med. 34(07), 1347-1357 (2004)

21. Beail, N., Williams, K.: Using qualitative methods in research with people who have intellectual disabilities. J. Appl. Res. Intellect. 27(2), 85-96 (2014)

22. Fitzgerald, C., Withers, P.: 'I don't know what a proper woman means': What women with intellectual disabilities think about sex, sexuality and themselves. British Journal of Learning Disabilities 41(1), 5$12(2013)$

23. Blanchflower, D.G., Oswald, A.J.: Money, sex and happiness: An empirical study. Scand. J. Econ. 106(3), $393-415(2004)$

24. Brown, I.: Embracing quality of life in times of spending restraint. J. Intellect. Dev. Dis. 24(4), 299-308 (1999)

25. Morentin, R., Arias, B., Jenaro, C., Rodríguez-Mayoral, J., McCarthy, M.: Love and loving relationships in people with learning disabilities: A scientific approach. Tizard Learning Disability Review 13(2), 33$41(2008)$

26. Brown, R.I.: Quality of life issues in aging and intellectual disability. Australia and New Zealand Journal of Developmental Disabilities 18(4), 219-227 (1993)

27. Cummins, R.A., Lau, A.L.: Community integration or community exposure? A review and discussion in relation to people with an intellectual disability. J. Appl. Res. Intellect. 16(2), 145-157 (2003)

28. Power, M., Green, A.: Development of the WHOQOL disabilities module. Qual. Life. Res. 19(4), 571-584 (2010) 
29. Schalock, R.L.: Reconsidering the conceptualisation and measurement of quality of life. In: Schalock, R. (ed.) Quality of Life: Conceptualisation and Measurement, vol. One. pp. 123-139. American Association of Mental Retardation, Washington, DC (1996)

30. Newton, J.S., Horner, R.H., Ard, W.R., LeBaron, N., Sappington, G.: A conceptual model for improving the social life of individuals with mental retardation. Ment. Retard. 32(6), 393 (1994)

31. Bayley, M.: What Price Friendship?: Encouraging the Relationships of People with Learning Difficulties. Hexagon Publishing, Wootton Courtenay (1997)

32. Emerson, E., Malam, S., Davies, I., Spencer, K.: Adults with Learning Disabilities in England 2003/4. London. Health and Social Care Information Centre, London (2005)

33. Office for National Statistics: 2011 Census, Key Statistics and Quick Statistics for Wards and Output Areas in England and Wales. http://webarchive.nationalarchives.gov.uk/20160105160709/http://www.ons.gov.uk/ons/publications/re -reference-tables.html?edition=tcm\%3A77-286348 (2013). Accessed 24th June 2016

34. Robertson, J., Emerson, E., Gregory, N., Hatton, C., Kessissoglou, S., Hallam, A., Linehan, C.: Social networks of people with mental retardation in residential settings. Ment. Retard. 39(3), 201-214 (2001)

35. Forrester-Jones, R., Carpenter, J., Coolen-Schrijner, P., Cambridge, P., Tate, A., Beecham, J., Hallam, A., Knapp, M., Wooff, D.: The social networks of people with intellectual disability living in the community 12 years after resettlement from long-stay hospitals. J. Appl. Res. Intellect. 19(4), 285-295 (2006)

36. Williams, F., Scott, G., McKechanie, A.: Sexual health services and support: The views of younger adults with intellectual disability. J. Intellect. Dev. Dis. 39(2), 147-156 (2014)

37. Frawley, P., Bigby, C.: "I'm in their shoes": Experiences of peer educators in sexuality and relationship education. J. Intellect. Dev. Dis. 39(2), 167-176 (2014)

38. Zigler, E.: Looking back 40 years and still seeing the person with mental retardation as a whole person. In: Switzky, H.N. (ed.) Personality and Motivational Differences in Persons with Mental Retardation. pp. 3-55. Lawrence Erlbaum, Mahwah, NJ (2001)

39. Zigler, E.: A veteran worker urges renewed research on personality factors in mental retardation. Japanese Journal of Special Education 39(6), 1-14 (2002) 
40. Kitson, D.: Concerns about people with learning disabilities being sexually abused. In: McCarthy, M.,

Thompson, D. (eds.) Sexuality and Learning Disability: A handbook pp. 125-140. Pavillion Publishing Brighton (2010)

41. McCarthy, M., Thompson, D. (eds.): Sexuality and Learning Disabilities: A Handbook. Pavilion Publishing, Brighton (2010)

42. Craft, A., Craft, M.: Handicapped Married Couples. Routledge \& Kegan Paul, London (1979)

43. Koller, H., Richardson, S., Katz, M.: Marriage in a young adult mentally retarded population. J. Intell. Disab. Res. 32(2), 93-102 (1988)

44. Mattinson, J.: Marriage and Mental Handicap. University of Pittsburgh Press, Pittsburgh (1971)

45. Grieve, A., McLaren, S., Lindsay, W., Culling, E.: Staff attitudes towards the sexuality of people with learning disabilities: a comparison of different professional groups and residential facilities. British Journal of Learning Disabilities 37(1), 76-84 (2009)

46. Shaw, R.L., Booth, A., Sutton, A.J., Miller, T., Smith, J.A., Young, B., Jones, D.R., Dixon-Woods, M.: Finding qualitative research: an evaluation of search strategies. BMC. Med. Res. Methodol. 4(1), 1 (2004)

47. Liberati, A., Altman, D.G., Tetzlaff, J., Mulrow, C., Gøtzsche, P.C., Ioannidis, J.P.A., Clarke, M., Devereaux, P.J., Kleijnen, J., Moher, D.: The PRISMA statement for reporting systematic reviews and meta-analyses of studies that evaluate health care interventions: Explanation and elaboration. J. Clin. Epidemiol. 62(10), e1-e34 (2009)

48. American Psychiatric Association (APA): Diagnostic and Statistical Manual of Mental Disorders, fifth ed. American Psychiatric Publishing, Arlington, VA (2013)

49. The Joanna Briggs Institute: The Joanna Briggs Institute Critical Appraisal tools for use in JBI Systematic Reviews: Checklist for Qualitative Research. http://joannabriggs.org/assets/docs/critical-appraisaltools/JBI_Critical_Appraisal-Checklist_for_Qualitative_Research.pdf (2016). Accessed 13th July 2016

50. Hannes, K., Lockwood, C., Pearson, A.: A comparative analysis of three online appraisal instruments' ability to assess validity in qualitative research. Qual. Health. Res. 20(12), 1736-1743 (2010)

51. Booth, T.A., Booth, W.: Parenting Under Pressure: Mothers and Fathers with Learning Difficulties. Open University, Buckingham (1994)

52. Higgins, J.P., Green, S.M. (eds.): Cochrane Handbook for Systematic Reviews of Interventions. WileyBlackwell, Chichester (2008) 
53. Dixon-Woods, M., Sutton, A., Shaw, R., Miller, T., Smith, J., Young, B., Bonas, S., Booth, A., Jones, D.: Appraising qualitative research for inclusion in systematic reviews: A quantitative and qualitative comparison of three methods. Journal of health services research \& policy 12(1), 42-47 (2007)

54. Noblit, G.W., Hare, R.D.: Meta-Ethnography: Synthesizing Qualitative Studies. Sage, London (1988)

55. Bane, G., Deely, M., Donohoe, B., Dooher, M., Flaherty, J., Iriarte, E.G., Hopkins, R., Mahon, A., Minogue, G., Donagh, P.M., Doherty, S.O., Curry, M., Shannon, S., Tierney, E., Wolfe, M.: Relationships of people with learning disabilities in Ireland. British Journal of Learning Disabilities 40(2), 109-122 (2012)

56. Bates, C., Terry, L., Popple, K.: Partner selection for people with intellectual disabilities. J. Appl. Res. Intellect. (2016) doi:10.1111/jar.12254

57. Healy, E., McGuire, B., Evans, D., Carley, S.: Sexuality and personal relationships for people with an intellectual disability. Part I: service-user perspectives. J. Intell. Disab. Res. 53(11), 905-912 (2009)

58. Heyman, B.: Sexuality as a perceived hazard in the lives of adults with learning difficulties. Disabil. Soc. 10(2), 139-156 (1995)

59. Johnson, K., Frawley, P., Hillier, L., Harrison, L.: Living safer sexual lives: Research and action. Tizard Learning Disability Review 7(3), 4-9 (2002)

60. Kelly, G., Crowley, H., Hamilton, C.: Rights, sexuality and relationships in Ireland: 'It'd be nice to be kind of trusted'. British Journal of Learning Disabilities 37(4), 308-315 (2009)

61. Knox, M., Hickson, F.: The meanings of close friendship: The views of four people with intellectual disabilities. J. Appl. Res. Intellect. 14(3), 276-291 (2001)

62. Lafferty, A., McConkey, R., Taggart, L.: Beyond friendship: The nature and meaning of close personal relationships as perceived by people with learning disabilities. Disabil. Soc. 28(8), 1074-1088 (2013)

63. Lesseliers, J., Van Hove, G.: Barriers to the development of intimate relationships and the expression of sexuality among people with developmental disabilities: Their perceptions. Res. Pract. Pers. Sev. D. 27(1), 69-81 (2002)

64. Neuman, R., Reiter, S.: Couple relationships as perceived by people with intellectual disability implications for quality of life and self-concept. International Journal of Developmental Disabilities, 110 (2016) doi:10.1080/20473869.2016.1173422

65. Rushbrooke, E., Murray, C., Townsend, S.: The experiences of intimate relationships by people with intellectual disabilities: A qualitative study. J. Appl. Res. Intellect. 27(6), 531-541 (2014) 
66. Sullivan, F., Bowden, K., McKenzie, K., Quayle, E.: 'Touching people in relationships': A qualitative study of close relationships for people with an intellectual disability. J. Clin. Nurs. 22(23-24), 3456-3466 (2013)

67. Turner, G.W., Crane, B.: Pleasure is paramount: Adults with intellectual disabilities discuss sensuality and intimacy. Sexualities 19(5-6), 677-697 (2016)

68. White, E., Barnitt, R.: Empowered or discouraged? A study of people with learning disabilities and their experience of engaging in intimate relationships. The British Journal of Occupational Therapy 63(6), $270-276(2000)$

69. Lesseliers, J.: A right to sexuality? British journal of learning disabilities 27(4), 137-140 (1999)

70. Sandelowski, M., Docherty, S., Emden, C.: Qualitative metasynthesis: Issues and techniques. Res. Nurs. Health. 20, 365-372 (1997)

71. Festinger, L.: A Theory of Cognitive Dissonance. Row, Peterson, Evanston, IL (1957)

72. Lloyd, V., Gatherer, A., Kalsy, S.: Conducting qualitative interview research with people with expressive language difficulties. Qual. Health. Res. 16(10), 1386-1404 (2006)

73. Estabrooks, C.A., Field, P.A., Morse, J.M.: Aggregating qualitative findings: An approach to theory development. Qual. Health. Res. 4(4), 503-511 (1994)

74. Jensen, L.A., Allen, M.N.: Meta-synthesis of qualitative findings. Qual. Health. Res. 6(4), 553-560 (1996) 